\title{
Kaempferol, a natural dietary flavonoid, suppresses $17 \beta$-estradiol-induced survivin expression and causes apoptotic cell death in endometrial cancer
}

\author{
AGAPITI HIPOLITI CHUWA ${ }^{1}$, KENBUN SONE ${ }^{1}$, KATSUTOSHI ODA ${ }^{1}$, \\ MICHIHIRO TANIKAWA $^{1}$, ASAKO KUKITA ${ }^{1}$, MACHIKO KOJIMA ${ }^{1}$, SHINYA OKI $^{1}$, \\ TOMOHIKO FUKUDA ${ }^{1}$, MAKOTO TAKEUCHI ${ }^{1}$, AKI MIYASAKA ${ }^{1}$, TOMOKO KASHIYAMA ${ }^{1}$, YUJI IKEDA ${ }^{1}$, \\ KAZUNORI NAGASAKA ${ }^{1}$, MAYUYO MORI-UCHINO ${ }^{1}$, YOKO MATSUMOTO ${ }^{1}$, OSAMU WADA-HIRAIKE ${ }^{1}$, \\ HIROYUKI KURAMOTO ${ }^{2}$, KEI KAWANA ${ }^{3}$, YUTAKA OSUGA ${ }^{1}$ and TOMOYUKI FUJII ${ }^{1}$ \\ ${ }^{1}$ Department of Obstetrics and Gynecology, Faculty of Medicine, University of Tokyo, Tokyo 113-8655; \\ ${ }^{2}$ Kanagawa Health Service Association, Kanagawa 231-0021; \\ ${ }^{3}$ Department of Obstetrics and Gynecology, Nihon University, Tokyo 173-8610, Japan
}

Received April 1, 2018; Accepted July 30, 2018

DOI: $10.3892 / 01.2018 .9340$

\begin{abstract}
Endometrioid endometrial carcinoma, commonly known as type 1 endometrial cancer, accounts for $>80 \%$ of endometrial carcinomas and is dependent on estrogen. We recently reported on the prognostic significance of the $B I R C 5$ survivin gene in endometrial cancer. Estradiol induces survivin expression in estrogen receptor-positive, but not in estrogen receptor-negative, cancer cells. Kaempferol, a bioflavonoid, reportedly inhibits estrogen receptor- $\alpha(E R \alpha)$ in hormone receptor-positive breast cancer cells. However, whether kaempferol-mediated inhibition of ER $\alpha$ suppresses survivin and induces cell death in endometrial cancer remains unclarified. The present study evaluated the antitumor effects of kaempferol on endometrial cancer cells. Cell viability
\end{abstract}

Correspondence to: Dr Kenbun Sone, Department of Obstetrics and Gynecology, Faculty of Medicine, University of Tokyo, 7-3-1 Hongo Bunkyo-ku, Tokyo 113-8655, Japan

E-mail: ksone5274@gmail.com

Abbreviations: Akt, protein kinase B; Bcl-2, B-cell lymphoma 2; CHIP, chromatin immunoprecipitation; DMSO, dimethyl sulfoxide; E2, 17 $\beta$-estradiol; EMEM, Eagle's minimum essential medium; ER $\alpha$, estrogen receptor- $\alpha$; FACS, fluorescence-activated cell sorting; FBS, fetal bovine serum; FITC, fluorescein isothiocyanate; IAP, inhibitor of apoptosis; IC50, half maximal inhibitory concentration; MDR1, multidrug resistance gene-1; MPA, medroxyprogesterone acetate; NgBR, Nogo-B receptor; PARP, poly adenosine diphosphate-ribose polymerase; PGC, proliferator-activated receptor $\gamma$ co-activator; PI, propidium iodide; PI3K, phosphatidylinositol-4,5-bisphosphate 3-kinase; PTEN, phosphatase and tensin homolog; XIAP, $\mathrm{X}$-chromosome linked inhibitor of apoptosis protein

Key words: kaempferol, 17 $\beta$-estradiol, estrogen receptor, survivin, endometrial cancer assays, flow cytometry analysis, western blotting and annexin $\mathrm{V}$ analyses were used to analyze the antitumor effects of kaempferol. The results demonstrated that kaempferol successfully suppressed the viability of two ER-positive endometrial cancer cell lines, with $\mathrm{IC}_{50}$ values of 83 and $65 \mu \mathrm{M}$. In addition, kaempferol induced sub-G1 cell accumulation and apoptotic cell death $(\mathrm{P}<0.01)$ in a dose-dependent manner. Treatment of cells with estradiol significantly induced co-expression of nuclear ER $\alpha$ and survivin proteins $(\mathrm{P}<0.001)$. Further evaluation revealed that kaempferol causes apoptotic cell death largely by suppressing ER $\alpha$, survivin and Bcl-2 protein. Therefore, the results of the present study suggested that targeting ER $\alpha$ and survivin with kaempferol may be a novel therapeutic option against endometrial carcinoma.

\section{Introduction}

Endometrial carcinoma is the most frequently diagnosed gynecologic malignancy in industrialized countries. The incidence of endometrial carcinoma is ascribed to the rising prevalence of nulliparity and metabolic diseases such as diabetes mellitus type 2 and obesity (1). Aromatization, a process in which androstenedione is converted to estrone in peripheral fat, is thought to be the main contributor to high levels of estrogen measured in obese women and significantly increases the risk of developing endometrial cancer (2). Almost $80 \%$ of diagnosed endometrial carcinomas are endometrioid adenocarcinomas (also known as type I cancers), which are strongly dependent on the stimulatory effects of estrogen $(3,4)$. A large proportion of these tumors are diagnosed in their early stages, and hysterectomies are the primary curative treatment modality (5). Although surgical management offers a favorable prognosis, advanced stage or recurrent disease responds poorly to standard therapies and thus has a poor prognosis (4). High-dose medroxyprogesterone acetate (MPA) has been approved for the treatment of type I endometrial carcinoma. However, up to $30 \%$ of patients with endometrial 
hyperplasia and endometrioid carcinoma are resistant to progestin therapy (6).

Our group and others previously reported on the frequency of mutated genes within the phosphatidylinositol-4,5-bisphosphate 3-kinase/phosphatase and tensin homolog/protein kinase B (PI3K/PTEN/AKT) survival pathway $(7,8)$. 17 $\beta$-Estradiol [E2; (17 $\beta$ )-estra-1,3,5 (10)-triene-3,17-diol] induces development of the majority of endometrial carcinomas, reportedly by activating phosphoinositide-3-kinase catalytic alpha (PIK3CA) polypeptides, suppressing PTEN, and upregulating survivin through estrogen receptor- $\alpha(\mathrm{ER} \alpha)$ signaling (9). Survivin, the smallest member of the inhibitor of apoptosis (IAP) protein family, is upregulated almost exclusively in malignant cells and is barely detectable in adult terminally-differentiated tissues. However, survivin is highly expressed in most human malignant tumors, including colorectal, esophageal, pancreatic, gastric, and others (10-12). E2 selectively upregulates survivin in hormone receptor-positive, but not receptor-negative cancer cells (13). Higher expression levels of survivin have been detected in over $83 \%$ of clinical endometrial cancer samples (14). We recently reported that survivin was overexpressed in over $87 \%$ of sixteen endometrial carcinoma cell lines tested and demonstrated that high expression of the BIRC5 survivin-encoding gene is an independent poor prognostic factor for endometrial carcinoma (15).

Kaempferol [3,5,7-trihydroxy-2-(4-hydroxyphenyl)$4 \mathrm{H}-1$-benzopyran-4-one] is a dietary bioflavonoid with anticancer, anti-inflammatory, and anti-oxidant properties that suppresses cell proliferation in human cancers through various mechanisms, including induction of tumor suppressor p53 and inhibition of ER $\alpha$ (16). Further, kaempferol reportedly binds to $\mathrm{ER} \alpha$, preventing its interaction with coactivator peroxisome proliferator-activated receptor gamma coactivator (PGC)-1 alpha. Antitumor effects associated with kaempferol have been reported in various human cancers, including osteosarcoma, breast, and ovarian cancers (17-19). However, the effects of kaempferol on endometrial carcinoma cells and whether the inhibitory effects of kaempferol against $\mathrm{ER} \alpha$ affect estradiol-induced survivin expression remain unclarified. Thus, we aimed to evaluate the antitumor effects of kaempferol on endometrial carcinoma cells, as well as its effect on survivin protein expression following suppression of $\operatorname{ER} \alpha$.

\section{Materials and methods}

Endometrial cancer cell lines. The estrogen receptor-positive Ishikawa cell line was kindly offered by Dr. Masato Nishida (Kasumigaura Medical Center, Ibaraki, Japan). The HEC-265 endometrial cancer cell line, also positive for estrogen receptors, and the HEC108 and HEC180 estrogen receptor-negative endometrial cancer cell lines were previously established by our co-author, Prof. Hiroyuki Kuramoto (20). The cell lines were maintained in Eagle's minimum essential medium (EMEM) containing 10\% fetal bovine serum (FBS) and antibiotics. Phenol red-free medium was used when estradiol was applied. Kaempferol was purchased from Sigma-Aldrich; Merck KGaA (Darmstadt, Germany) and stored as a $10 \mathrm{mM}$ stock solution at $-20^{\circ} \mathrm{C}$ in the dark.
Cell viability assay. Cells were cultured in 96-well plates ( $2 \times 10^{3}$ cells per well) in an appropriate medium for $24 \mathrm{~h}$ in a humidified incubator $\left(37^{\circ} \mathrm{C}\right.$ and $\left.5 \% \mathrm{CO}_{2}\right)$ to allow for attachment. The medium was then removed and fresh medium containing an increasing concentration of kaempferol was added, after which the cells were incubated for another $72 \mathrm{~h}$. To perform a MTT assay, $10 \mu \mathrm{l}$ of Cell Count Kit-8 solution (Dojindo Molecular Technologies, Inc., Kumamoto, Japan) was added to each well, and the cells were incubated for $3 \mathrm{~h}$ before being analyzed. At that point, a microplate reader (BioTek Instruments, Inc., Winooski, VT, USA) was used to measure the change in absorbance at $450 \mathrm{~nm}$. Measurements of cells treated only with dimethyl sulfoxide (DMSO) were used for normalization. This experiment was performed at least three times.

Cell cycle analysis. Cells were cultured in 6-cm dishes ( $4 \times 10^{5}$ cells per dish) for $24 \mathrm{~h}$, after which the medium was replaced with fresh medium containing DSMO (control), $36 \mu \mathrm{M}$ kaempferol, or $72 \mu \mathrm{M}$ kaempferol and further incubated at $37^{\circ} \mathrm{C}$ and $5 \% \mathrm{CO}_{2}$ for $48 \mathrm{~h}$. Cells were then collected and processed as previously described $(21,22)$. Cell cycle progression was performed via fluorescence-activated cell sorting (FACS) with an Epics XL instrument (Beckman Coulter, Inc., Brea, CA, USA) and CellQuest Pro v.3.1 software (BD Biosciences, Franklin Lakes, NJ, USA). This experiment was performed at least three times.

Apoptosis evaluation. Cells were plated in 60-mm dishes ( $4 \times 10^{5}$ cells per dish) and incubated for $24 \mathrm{~h}$. The medium was then replaced with fresh medium containing DMSO (control), $36 \mu \mathrm{M}$ kaempferol, or $72 \mu \mathrm{M}$ kaempferol and incubated at $37^{\circ} \mathrm{C}$ and $5 \% \mathrm{CO}_{2}$ for another $48 \mathrm{~h}$. Estradiol (10 nM final concentration) was added to the cells $3 \mathrm{~h}$ prior to harvesting. Cells were collected and processed as discussed elsewhere (23). Annexin V-fluorescein isothiocyanate (FITC)/propidium iodide (PI) double-positive cells are expressed as a percentage of apoptotic cells, as determined via flow cytometry. The experiment was repeated at least three times. Western blotting. Western blots (Bio-Rad Laboratories, Inc., Hercules, CA, USA) were used to analyze protein samples extracted from cells that were treated with DMSO (control), $36 \mu \mathrm{M}$ kaempferol, or $72 \mu \mathrm{M}$ kaempferol for $48 \mathrm{~h}$ and then $10 \mathrm{nM}$ of E2 for $3 \mathrm{~h}$. A ProteoExtract subcellular proteome extraction kit (Calbiochem; EMD Biosciences, Inc., Merck KGaA, Darmstadt, Germany) was used to differentially extract proteins according to their subcellular (i.e., membrane, cytosol, or nuclear) localization. Primary antibodies for the following compounds were used to probe the membranes: ER $\alpha$ (D-12), p53 (Santa Cruz Biotechnology, Inc., Dallas, TX, USA), survivin (71G4B7), B-cell lymphoma 2 (Bcl-2) protein, and cleaved poly adenosine diphosphate-ribose polymerase (PARP; Cell Signaling Technology, Inc., Danvers, MA, USA). The antibody-detecting housekeeping protein $\beta$-actin (Sigma-Aldrich; Merck KGaA) was used as a loading control. All antibodies were used in compliance with manufacturers' recommendations after protein bands were enhanced with ECL Select Solutions A and B (GE Healthcare Life Sciences, Piscataway, NJ, USA).

Statistical analysis. Statistical significance of differences between groups was evaluated with one-way analysis of 
A

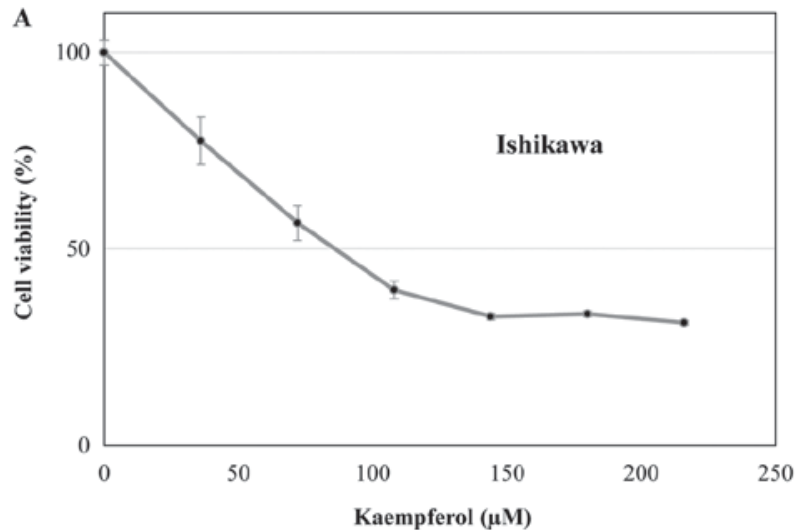

C

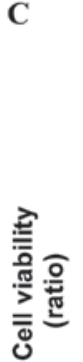

HEC108

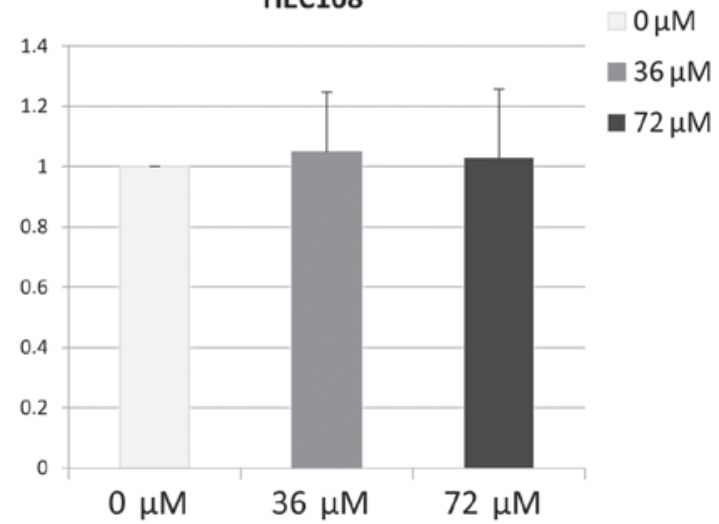

B

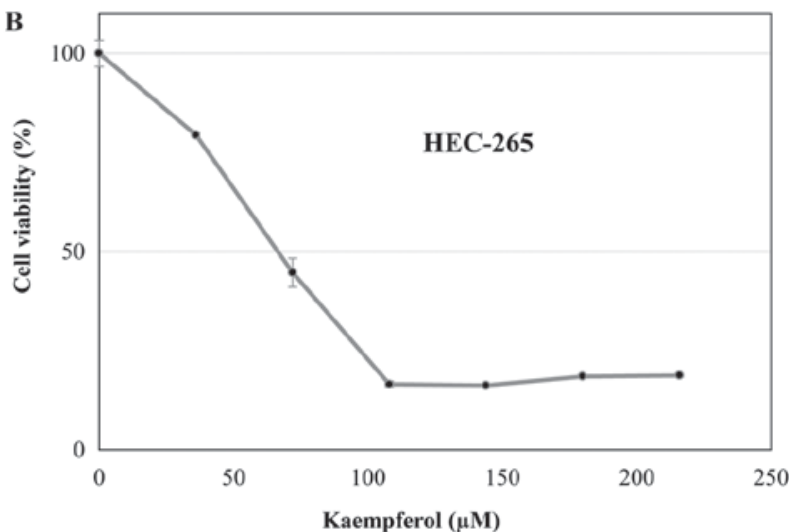

D

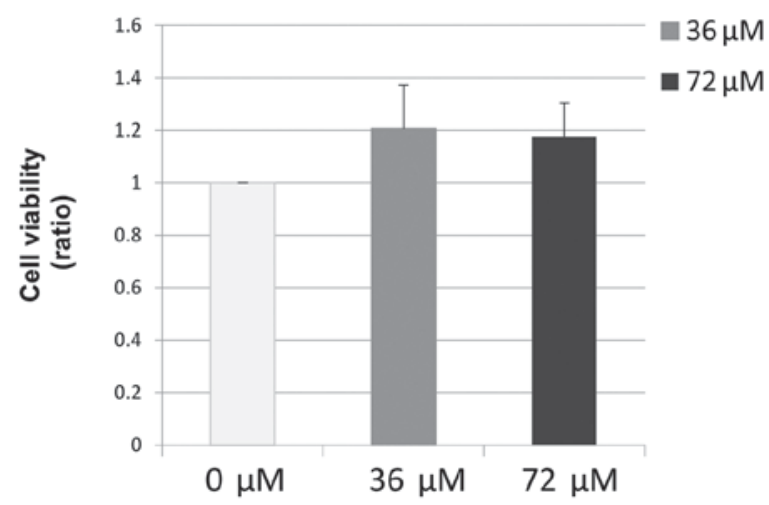

Figure 1. Kaempferol suppresses growth of Ishikawa and HEC-265 estrogen receptor-positive endometrial cancer cells. Growth inhibition in. (A) Ishikawa and (B) HEC265 endometrial cancer cells, with an $\mathrm{IC}_{50}$ of 83 and $65 \mu \mathrm{M}$, respectively. Kaempferol did not suppress the growth of HEC108 or HEC180 estrogen receptor-negative endometrial cancer cells. Cell viability in (C) HEC108 and (D) HEC180 endometrial cancer. IC $_{50}$, half-maximal inhibitory concentration.

variance with Tukey's post hoc test using JMP Pro. v.12 (SAS Institute, Inc., Cary, NC, USA) and GraphPad Prism 6 (GraphPad Software, Inc., La Jolla, CA, USA) software. ImageJ v.1.48 software (NIH, Bethesda, Maryland, USA) was used to quantify protein expression bands. $\mathrm{P}<0.05$ was considered to indicate a statistically significant difference.

\section{Results}

Kaempferol suppresses viability of Ishikawa and HEC-265 cells. Cell viability assays were performed to assess the growth inhibitory effects of kaempferol against Ishikawa and HEC-265 estrogen receptor-positive endometrial cancer cells. Kaempferol successfully suppressed the growth of Ishikawa and HEC-265 cells, with $\mathrm{IC}_{50}$ values of 83 and $65 \mu \mathrm{M}$, respectively (Fig. 1A and B). We further examined the anti-tumor effects of kaempferol in HEC108 and HEC180 estrogen receptor-negative endometrial cancer cells. Kaempferol did not suppress the growth of HEC108 and HEC180 cells (Fig. 1C and D).

Kaempferol induces sub-G1 and G2/M phases of the cell cycle. To understand the mechanisms by which kaempferol suppresses cell growth in endometrial carcinoma, cells treated with varying concentrations of kaempferol were incubated for $48 \mathrm{~h}$ and then evaluated via FACS for cell cycle progression. We found that kaempferol induced cell accumulation in the
sub-G1 and G2/M phases in Ishikawa and HEC-265 endometrial cancer cells, while significantly suppressing the G1 phase $(\mathrm{P}<0.01$; Fig. 2A and $\mathrm{B})$.

Kaempferol induces apoptotic cell death in endometrial cancer by suppressing ER $\alpha$, survivin and Bcl-2. We evaluated the cytotoxicity of kaempferol against endometrial cancer cells and possible mechanisms by analyzing the induction of apoptosis using an annexin V-FITC/PI assay. We found that kaempferol significantly $(\mathrm{P}<0.01)$ induced apoptotic cell death in Ishikawa and HEC-265 cells (Fig. 3A). Further analysis via western blot revealed that kaempferol induced apoptosis largely by suppressing $\mathrm{ER} \alpha$ and the antiapoptotic proteins survivin and Bcl-2 and by inducing p53 and PARP cleavage (Fig. 3B).

E2 significantly induces nuclear co-expression of ER $\alpha$ and survivin in endometrial cancer cells. To investigate the site of action of E2 and its role in ER $\alpha$ and survivin activity in subcellular compartments, subcellular protein samples were extracted from Ishikawa and HEC-265 cells treated with E2 and/or kaempferol and analyzed via western blot. E2 significantly induced co-expression of nuclear ER $\alpha$ and survivin (Fig. 4A). This result suggests that E2 primarily induces nuclear ER $\alpha$ and survivin, consequently preventing apoptosis. Treatment of cells with kaempferol inhibited estradiol-induced upregulation of survivin and led to apoptotic cell death (Fig. 4B). 

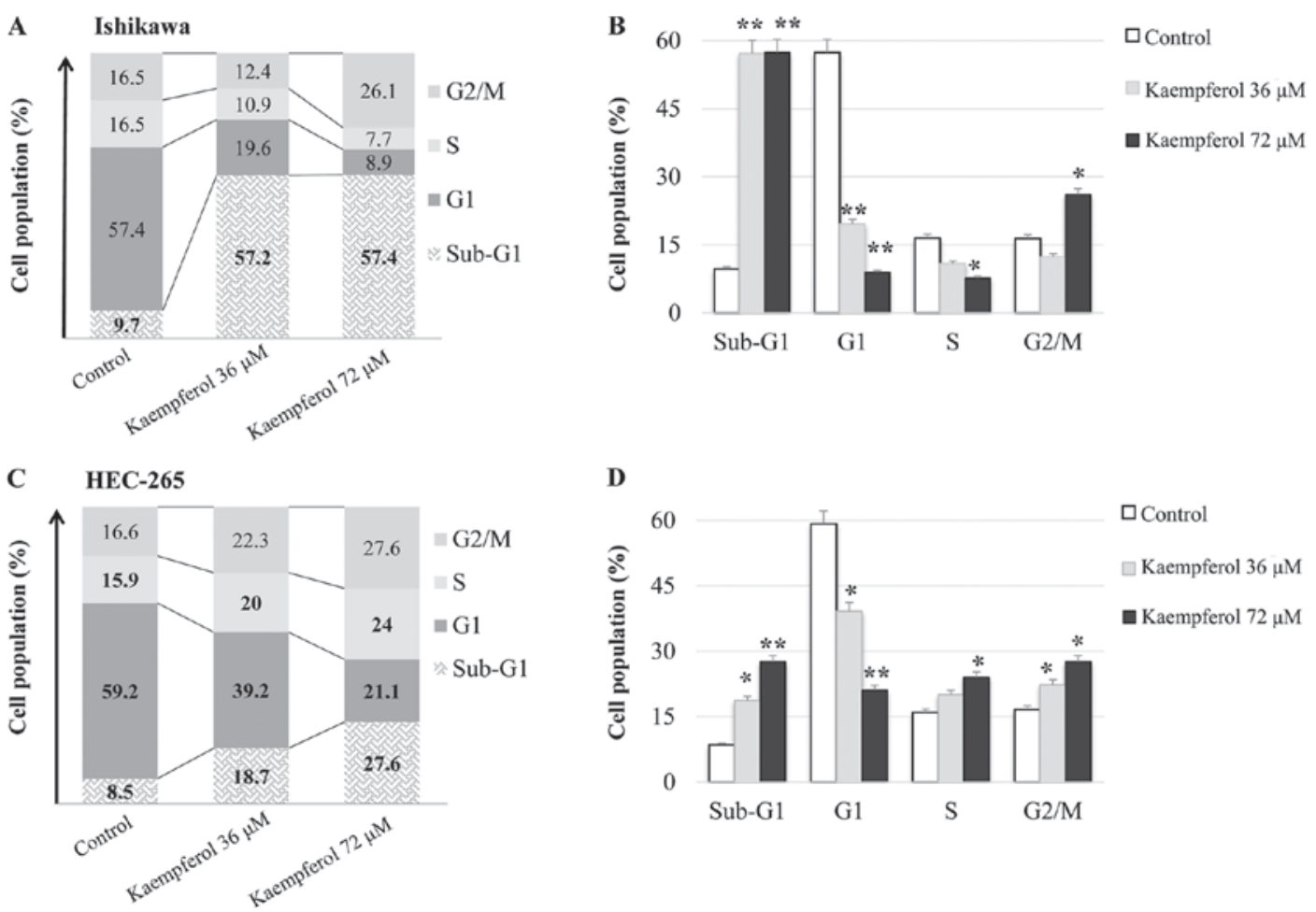

Figure 2. Effects of kaempferol on Ishikawa and HEC-265 cell cycle progression. Kaempferol induction of sub-G1 and G2/M phases as a measure of the cell population percentage in (A and B) Ishikawa and (C and D) HEC-265 endometrial cancer cells. ${ }^{*} \mathrm{P}<0.05$ and ${ }^{* * *} \mathrm{P}<0.01$ vs. control. Kaemp, kaempferol.

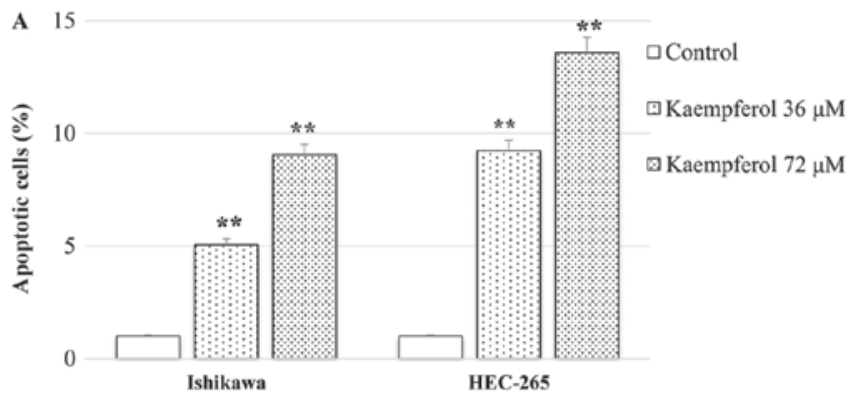

B

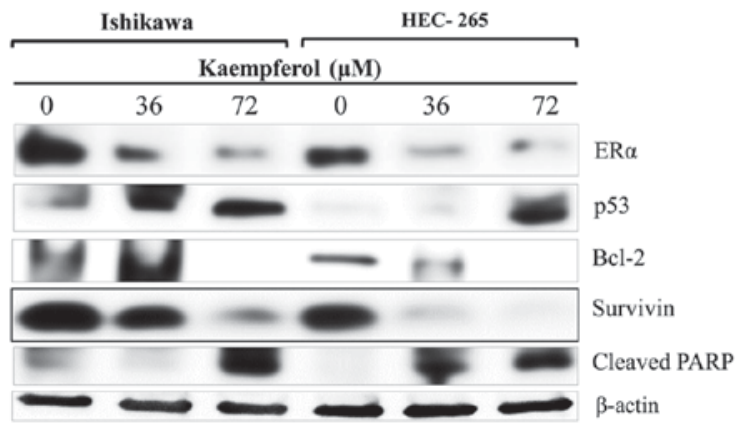

Figure 3. Induction of apoptosis by kaempferol. (A) Significant induction of apoptosis in Ishikawa and HEC-265 endometrial cancer cell lines. (B) Kaempferol suppressed ER $\alpha, \mathrm{Bcl}-2$ and survivin, and induced p53 and cleaved PARP expression. ${ }^{* *} \mathrm{P}<0.01$ vs. control. PARP, poly adenosine diphosphate-ribose polymerase; $\mathrm{ER} \alpha$, estrogen receptor $\alpha$; Bcl-2, B-cell lymphoma 2.

\section{Discussion}

Targeting ER $\alpha$ in endometrial cancer using kaempferol may be a feasible therapeutic strategy, as ER $\alpha$-mediated oncogenic effects, including upregulation of Nogo-B receptor $(\mathrm{NgBR})$ and survivin, as well as activation of the $\mathrm{PI} 3 \mathrm{~K} / \mathrm{mTOR} / \mathrm{Akt}$ pathway have been established $(13,24)$. Moreover, ER $\alpha$ is known to interact with survivin and p53. Studies have demonstrated that ER $\alpha$ interacts in vivo with $\mathrm{p} 53$ bound to promoters of survivin and multidrug resistance gene-1 (MDR1), both of which are p53-transcriptional repression targets $(24,25)$. Additionally, ER $\alpha$ can directly bind to $\mathrm{p} 53$, which plays an important role in mediating apoptosis and leads to downregulation of p53-mediated transcriptional activation.

Survivin interacts with p53 such that wild-type p53 suppresses the expression of survivin by blocking transcription of the BIRC5 survivin gene (26). Furthermore, the resistance of cancer cells to apoptosis is attributable to upregulation of survivin via its promoter, which results from loss of the p53 tumor suppressor. Survivin inhibits apoptosis through several mechanisms, including direct binding and inhibition of caspases-3 and -9, synergizing with the X-chromosome-linked inhibitor of apoptosis protein (XIAP), binding to the pro-apoptotic protein secondary mitochondria-derived activator of caspase/direct inhibitor of apoptosis-binding protein with low pI (SMAC/DIABLO), and by preventing-activation of the procaspases $(26,27)$. Steroids are known to trigger translocation of cytoplasmic ERs to the nucleus (28); however, there is limited knowledge about the mechanisms involved and the resulting effects.

The Wnt signaling pathway plays an important role in stem cells and is responsible for regulation of survivin expression. Thus, survivin antagonists may affect cancer stem cells (29). Although there are various apoptosis-based cancer therapies (30), targeting survivin provides several advantages. Suppressing survivin compromises not only the anti-apoptotic cascade, but 


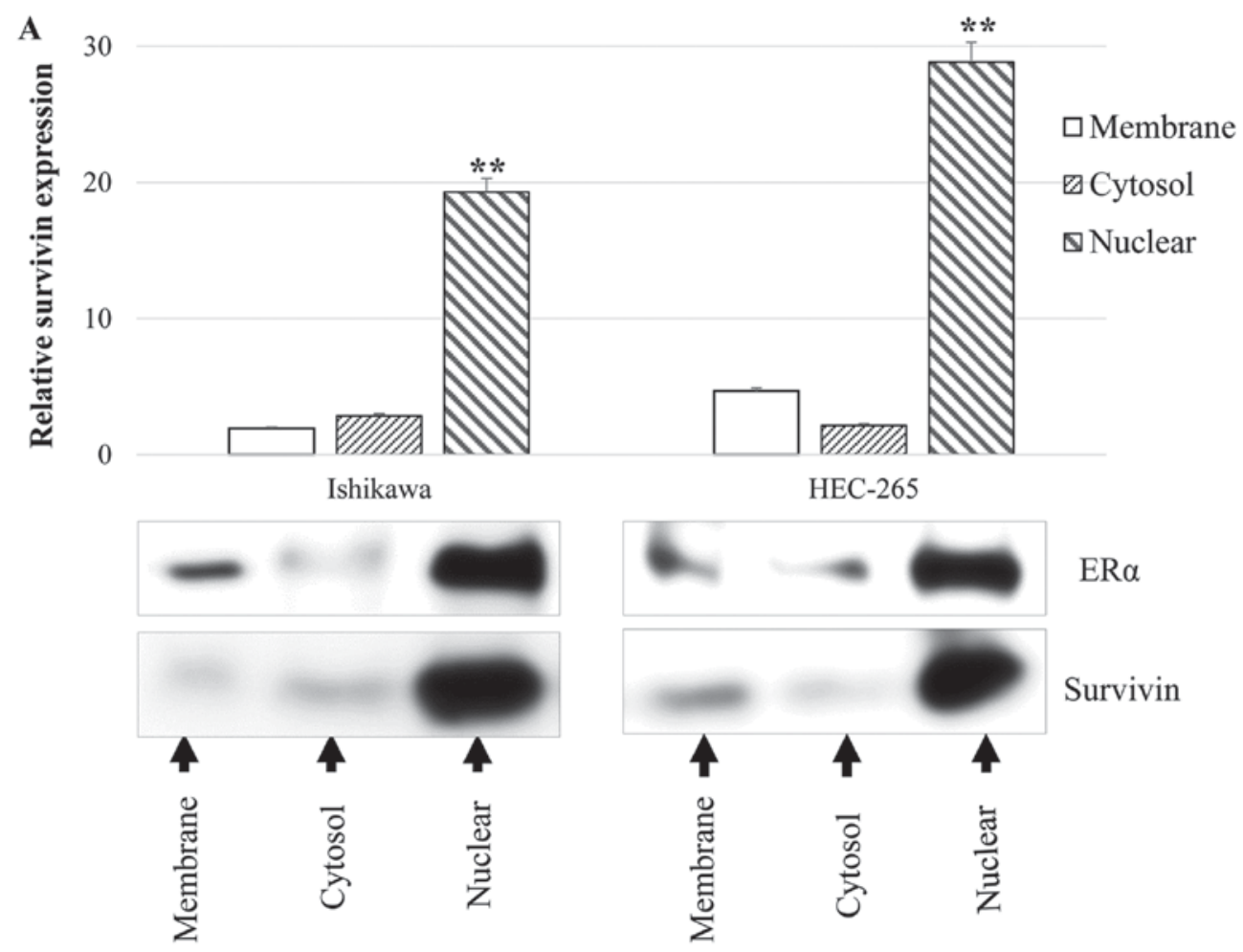

B HEC- 265:

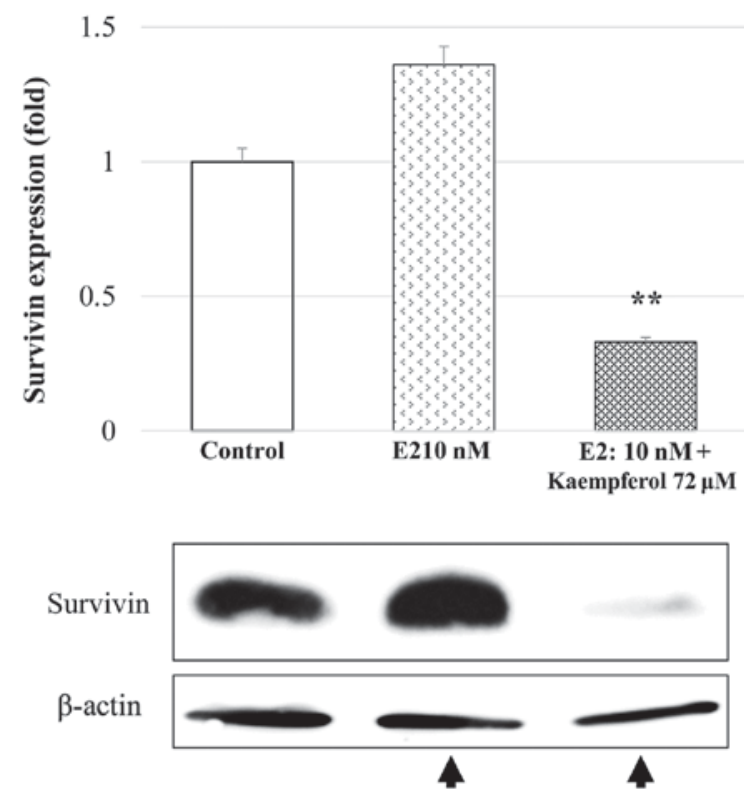

Figure 4. Effects of kaempferol on survivin protein expression. (A) Estradiol induces nuclear co-expression of ER $\alpha$ and survivin in Ishikawa and HEC-265 endometrial cancer cells. Arrows indicate treatment with E2 (10 nM). (B) Kaempferol inhibited E2-induced survivin expression in the HEC-265 endometrial carcinoma cell line. Arrows indicate treatment with E2 (10 nM). ${ }^{* *} \mathrm{P}<0.01$ vs. control. ER $\alpha$, estrogen receptor $\alpha$; E2, 17 $\beta$-estradiol.

also the multiple cellular signaling networks required to maintain tumors and their microenvironments (31). Additionally, targeting survivin does not affect normal cells or tissues. For instance, a phase I clinical trial of a survivin-based vaccination has been completed using immunologic antigen-specific responses in which no side effects were reported $(32,33)$. Thus, survivin-based therapeutics might possess more favorable toxicity profiles than other treatment options.

The findings of this study provide a novel therapeutic strategy for endometrial cancer treatment using kaempferol, a natural dietary flavonoid. This approach offers additional merits attributable to the readily availability and affordability of kaempferol and because kaempferol effectively targets E2-induced/ER $\alpha$-mediated oncogenic signaling pathways, which play a crucial role in tumorigenesis of most endometrial carcinomas. As we proposed in Fig. 5, kaempferol inhibits $\mathrm{ER} \alpha$, leading to suppression of survivin and apoptotic cell death, in addition to inducing p53, which was reported previously (34-36). Results show that kaempferol had no antitumor effects against estrogen receptor-negative endometrial cancer 


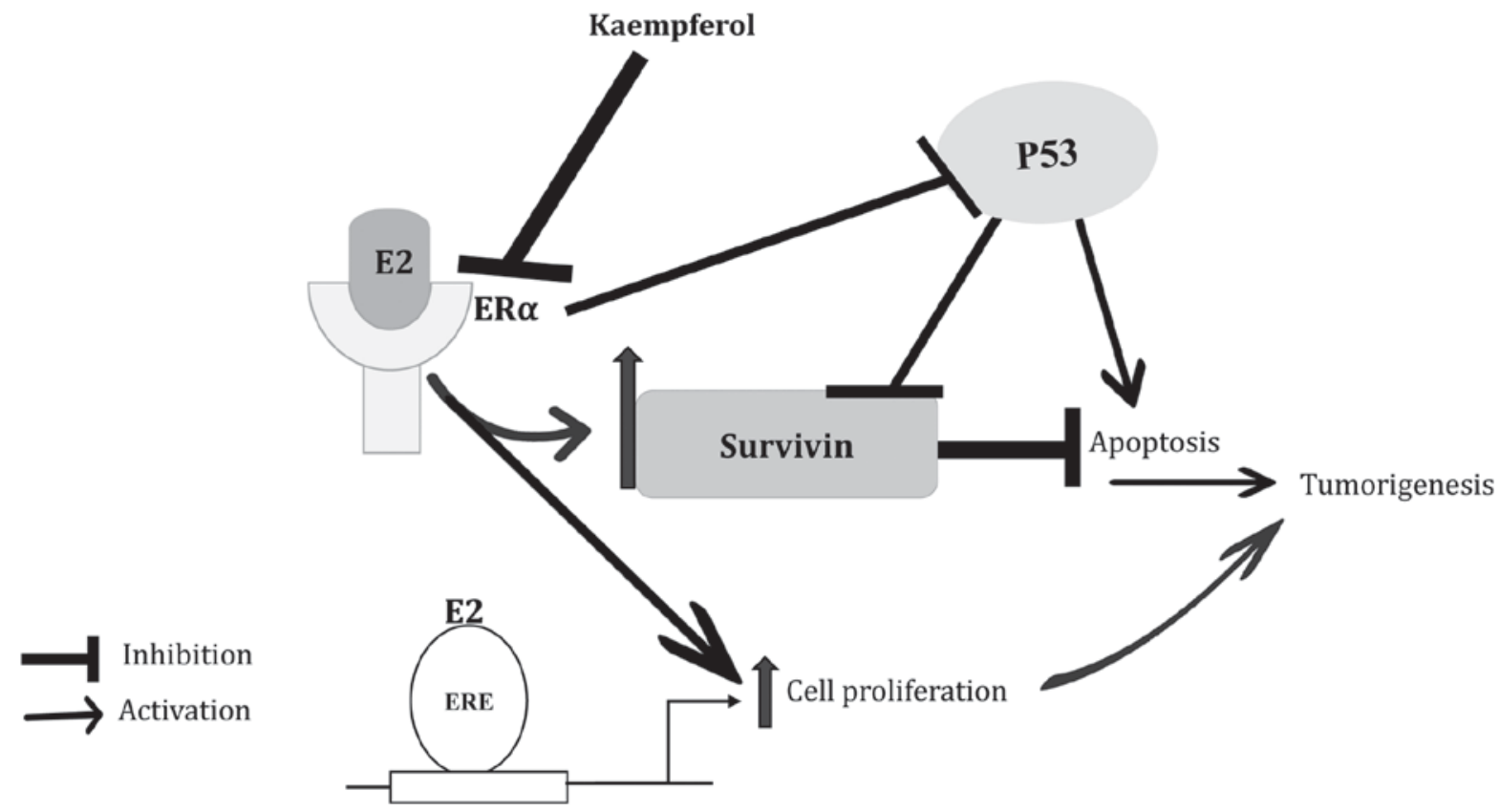

Figure 5. Proposed model for the role of kaempferol in endometrial cancer cells and possible mechanisms. E2, 17 $\beta$-estradiol; ER $\alpha$, estrogen receptor- $\alpha$; ERE, estrogen responsive elements.

cells. These results further support our proposed mechanism. While other survivin antagonists have been described, kaempferol provides added benefits because ER $\alpha$ is upstream of survivin and can activate unrelated pathways. Furthermore, as a phytoestrogen, kaempferol may offer a more favorable toxicity profile than other survivin-based therapeutics.

This study has some limitations. First, there are no biomarkers for predicting the sensitivity of endometrial carcinoma to kaempferol. Second, ex-vivo experiments may be required to further clarify the antitumor effects of kaempferol in endometrial cancer. Finally, the effectiveness and tolerability of kaempferol must be assessed in patients with endometrial carcinomas in clinical trials.

The present study demonstrates the potential antitumor effects of kaempferol against endometrial carcinoma cells. Therefore, further research into its development as a novel molecularly-targeted agent against endometrial carcinoma is recommended.

\section{Acknowledgements}

The authors would like to thank Miss Kaori Tomita (Department of Obstetrics and Gynecology, Faculty of Medicine, University of Tokyo, Tokyo, Japan) for providing support and assistance; Dr. Masato Nishida (Kasumigaura Medical Center, Ibaraki, Japan) and Professor Satoru Kyo (Shimane University Faculty of Medicine, Shimane, Japan) for providing Ishikawa and endometrial immortalized cells, respectively.

\section{Funding}

The present study was financially supported by a Grant-in-Aid for Scientific Research (grant nos. 26462515, 17K11269 and 15K10705), and Grants-in-Aid for Young Scientific Research from the Ministry of Education, Culture, Sports, Science and Technology of Japan (grant nos. 15K20128, 16H06757, $16 \mathrm{~K} 21330,17 \mathrm{~K} 16832$ and 16K20176); the present study was also partially supported by AMED (grant no. JP17cm0106502).

\section{Availability of data and materials}

The datasets used and/or analyzed during the current study are available from the corresponding author on reasonable request.

\section{Authors' contributions}

AHC, KS and KO conceived and designed the study. SO, TF, MT, AM, TK and YI designed the experiments. AK and MK performed the cell viability assay, and all of the other experiments were performed by AHC. AHC and KS acquired the data. The data were analyzed and interpreted by AHC, $\mathrm{KS}, \mathrm{KO}, \mathrm{MT}, \mathrm{KN}, \mathrm{YM}, \mathrm{OH}, \mathrm{KK}, \mathrm{YO}$ and TF. AHC and KS prepared the manuscript and figures. AHC, KS, KO, YO and TF reviewed and revised the manuscript for important intellectual content. Technical and material support was provided by AK, MK, MU, TF and HK. HK and MU reviewed the manuscript for important intellectual content. MU analyzed and interpreted the data in additional experiments. HK established and provided endometrial cancer cell lines used in the study. All of the authors approved the final version of this manuscript.

\section{Ethics approval and consent to participate}

Not applicable.

\section{Patient consent for publication}

Not applicable. 


\section{Competing interests}

The authors declare that they have no competing interests.

\section{References}

1. Bokhman JV: Two pathogenetic types of endometrial carcinoma. Gynecol Oncol 15: 10-17, 1983.

2. Schenker JG, Weinstein D and Okon E: Estradiol and testosterone levels in the peripheral and ovarian circulations in patients with endometrial cancer. Cancer 44: 1809-1812, 1979.

3. Yang HP, Gonzalez Bosquet J, Li Q, Platz EA, Brinton LA, Sherman ME, Lacey JV Jr, Gaudet MM, Burdette LA, Figueroa JD, et al: Common genetic variation in the sex hormone metabolic pathway and endometrial cancer risk: Pathway-based evaluation of candidate genes. Carcinogenesis 5: 827-833, 2010.

4. Hernandez E: Pathological findings and prognosis from uterine malignancy. Curr Opinion Obstet Gynecol 5: 480-485, 1993.

5. Lachance JA, Darus CJ and Rice LW: Surgical management and postoperative treatment of endometrial carcinoma. Rev Obstet Gynecol 1: 97-105, 2008

6. Chaudhry P and Asselin E: Resistance to chemotherapy and hormone therapy in endometrial cancer. Endocr Relat Cancer 16 363-380, 2009

7. Oda K, Stokoe D, Taketani Y and McCormick F: High frequency of coexistent mutations of PIK3CA and PTEN genes in endometrial carcinoma. Cancer Res 65: 10669-10673, 2005.

8. Chen J, Zhao KN, Li R, Shao R and Chen C: Activation of PI3K/Akt/mTOR pathway and dual inhibitors of PI3K and mTOR in endometrial cancer. Curr Med Chem 21: 3070-3080, 2014.

9. Scully MM, Palacios-Helgeson LK, Wah LS and Jackson TA: Rapid estrogen signaling negatively regulates PTEN activity through phosphorylation in endometrial cancer cells. Horm Cancer 5: 218-231, 2014.

10. Jaiswal PK, Goel A and Mittal RD: Survivin: A molecular biomarker in cancer. Indian J Med Res 141: 389-397, 2015.

11. Ryan BM, O'Donovan N and Duffy MJ: Survivin: A new target for anti-cancer therapy. Cancer Treat Rev 35: 553-562, 2009

12. Altieri DC: Targeting survivin in cancer. Cancer Lett 332 225-228, 2013.

13. Wang B, Zhao B, North P, Kong A, Huang J and Miao QR Expression of NgBR is highly associated with estrogen receptor alpha and survivin in breast cancer. PLoS One 8: e78083, 2013.

14. Erkanli S, Kayaselcuk F, Kuscu E, Bagis T, Bolat F, Haberal A and Demirhan B: Expression of survivin, PTEN and p27 in normal, hyperplastic, and carcinomatous endometrium. Int $\mathrm{J}$ Gynecol Cancer 16: 1412-1418, 2006.

15. Chuwa AH, Sone K, Oda K, Ikeda Y, Fukuda T, Wada-Hiraike O, Inaba K, Makii C, Takeuchi M, Oki S, et al: Significance of survivin as a prognostic factor and a therapeutic target in endometrial cancer. Gynecol Oncol 141: 564-569, 2016.

16. Luo H, Rankin GO, Li Z, DePriest L and Chen YC: Kaempferol induces apoptosis in ovarian cancer cells through activating p53 in intrinsic pathway. Food Chem 128: 513-519, 2011.

17. Hung $\mathrm{H}$ : Inhibition of estrogen receptor alpha expression and function in MCF-7 cells by kaempferol. J Cell Physiol 198: 197-208, 2004.

18. Luo H, Rankin GO, Liu L, Daddysman MK, Jiang BH and Chen YC: Kaempferol inhibits angiogenesis and VEGF expression through both HIF dependent and independent pathways in human ovarian cancer cells. Nutr Cancer 61: 554-563, 2009.

19. Chen HJ, Lin CM, Lee CY, Shih NC, Peng SF, Tsuzuki M, Amagaya S, Huang WW and Yang JS: Kaempferol suppresses cell metastasis via inhibition of the ERK-p38-JNK and AP-1 signaling pathways in U-2 OS human osteosarcoma cells. Oncol Rep 30: 925-932, 2013.
20. Kuramoto H, Nishida M, Morisawa T, Hamano M, Hata H, Kato Y, Ohno E and lida T: Establishment and characterization of human endometrial cancer cell lines. Ann N Y Acad Sci 622: 402-421, 1991.

21. Inaba K, Oda K, Aoki K, Sone K, Ikeda Y, Miyasaka A, Kashiyama T, Fukuda T, Makii C, Arimoto T, et al: Synergistic antitumor effects of combination PI3K/mTOR and MEK inhibition (SAR245409 and pimasertib) in ovarian carcinoma cells by fluorescence resonance energy transfer imaging. Oncotarget 7 : 29577-29591, 2016.

22. Fukuda T, Oda K, Wada-Hiraike O, Sone K, Inaba K, Ikeda Y, Makii C, Miyasaka A, Kashiyama T, Tanikawa M, et al: Autophagy inhibition augments resveratrol-induced apoptosis in Ishikawa endometrial cancer cells. Oncol Lett 12: 2560-2566, 2016.

23. Stoica GE, Franke TF, Moroni M, Mueller S, Morgan E, Iann MC, Winder AD, Reiter R, Wellstein A, Martin MB and Stoica A: Effect of estradiol on estrogen receptor-alpha gene expression and activity can be modulated by the ErbB2/PI 3-K/Akt pathway. Oncogene 22: 7998-8011, 2003.

24. Sayeed A, Konduri SD, Liu W, Bansal S, Li F and Das GM: Estrogen receptor alpha inhibits p53-mediated transcriptional repression: Implications for the regulation of apoptosis. Cancer Res 67: 7746-7755, 2007.

25. Hoffman WH, Biade S, Zilfou JT, Chen J and Murphy M: Transcriptional repression of the anti-apoptotic survivin gene by wild-type p53. J Biol Chem 277: 3247-3257, 2002.

26. Johnson ME and Howerth EW: Survivin: A bifunctional inhibitor of apoptosis protein. Vet Pathol 41: 599-607, 2004.

27. Mita AC, Mita MM, Nawrocki ST and Giles FJ: Survivin: Key regulator of mitosis and apoptosis and novel target for cancer therapeutics. Clin Cancer Res 14: 5000-5005, 2008.

28. Raam S, Richardson GS, Bradley F, MacLaughlin D, Sun L, Frankel F and Cohen JL: Translocation of cytoplasmic estrogen receptors to the nucleus: Immunohistochemical demonstration utilizing rabbit antibodies to estrogen receptors of mammary carcinomas. Breast Cancer Res Treat 3: 179-199, 1983.

29. Reya T, Morrison SJ, Clarke MF and Weissman IL: Stem cells, cancer, and cancer stem cells. Nature 414: 105-111, 2001.

30. Reed JC: Apoptosis-targeted therapies for cancer. Cancer Cell 3: 17-22, 2003.

31. Sawyers C: Targeted cancer therapy. Nature 432: 294-297, 2004.

32. Hirschowitz EA, Foody T, Kryscio R, Dickson L, Sturgill J and Yannelli J: Autologous dendritic cell vaccines for non-small-cell lung cancer. J Clin Oncol 22: 2808-2815, 2004.

33. Otto K, Andersen MH, Eggert A, Keikavoussi P, Pedersen L $\varnothing$, Rath JC, Böck M, Bröcker EB, Straten PT, Kämpgen E and Becker JC: Lack of toxicity of therapy-induced $\mathrm{T}$ cell responses against the universal tumour antigen survivin. Vaccine 23: 884-889, 2005 .

34. Li W, Du B, Wang T, Wang S and Zhang J: Kaempferol induces apoptosis in human HCT116 colon cancer cells via the Ataxia-Telangiectasia Mutated-p53 pathway with the involvement of p53 upregulated modulator of apoptosis. Chem Biol Interact 177: 121-127, 2009.

35. Kim SH and Choi KC: Anti-cancer effect and underlying mechanism(s) of kaempferol, a phytoestrogen, on the regulation of apoptosis in diverse cancer cell models. Toxicol Res 29: 229-234, 2013.

36. Lee CF, Yang JS, Tsai FJ, Chiang NN, Lu CC, Huang YS, Chen C and Chen FA: Kaempferol induces ATM/p53-mediated death receptor and mitochondrial apoptosis in human umbilical vein endothelial cells. Int J Oncol 48: 2007-2014, 2016. 